\title{
Cultured Horse Articular Chondrocytes in 3D-Printed Chitosan Scaffold With Hyaluronic Acid and Platelet Lysate
}

\author{
Elena De Angelis ${ }^{1 \dagger}$, Roberta Saleri ${ }^{1}$, Paolo Martelli ${ }^{1}$, Lisa Elviri ${ }^{2}$, Annalisa Bianchera ${ }^{2}$, \\ Carlo Bergonzi ${ }^{2}$, Marta Pirola ${ }^{1}$, Roberta Romeo ${ }^{1}$, Melania Andrani ${ }^{1}$, Valeria Cavalli ${ }^{1}$, \\ Virna Conti ${ }^{1}$, Ruggero Bettini ${ }^{2}$, Benedetta Passeri ${ }^{1}$, Francesca Ravanetti ${ }^{1 *}$ and \\ Paolo Borghetti ${ }^{1+}$ \\ ${ }^{1}$ Department of Veterinary Science, University of Parma, Parma, Italy, ${ }^{2}$ Food and Drug Department, University of Parma, \\ Parma, Italy
}

\section{OPEN ACCESS}

Edited by:

Debbie Guest,

Royal Veterinary College (RVC),

United Kingdom

Reviewed by:

Gundula Gesine Schulze-Tanzil,

Paracelsus Medical University, Austria

Kyla Ortved,

University of Pennsylvania,

United States

*Correspondence:

Francesca Ravanett

francesca.ravanetti@unipr.it

†These authors have contributed equally to this work

Specialty section:

This article was submitted to Veterinary Regenerative Medicine,

a section of the journal

Frontiers in Veterinary Science

Received: 24 February 2021

Accepted: 14 May 2021

Published: 12 July 2021

Citation:

De Angelis E, Saleri R, Martelli $P$.

Elviri L, Bianchera A, Bergonzi C

Pirola $M$, Romeo R, Andrani $M$, Cavalli V, Conti V, Bettini R, Passeri B,

Ravanetti F and Borghetti $P$ (2021)

Cultured Horse Articular

Chondrocytes in 3D-Printed Chitosan

Scaffold With Hyaluronic Acid and

Platelet Lysate.

Front. Vet. Sci. 8:671776

doi: 10.3389/fvets.2021.671776
Three-dimensional (3D) printing has gained popularity in tissue engineering and in the field of cartilage regeneration. This is due to its potential to generate scaffolds with spatial variation of cell distribution or mechanical properties, built with a variety of materials that can mimic complex tissue architecture. In the present study, horse articular chondrocytes were cultured for 2 and 4 weeks in 3D-printed chitosan (CH)-based scaffolds prepared with or without hyaluronic acid and in the presence of fetal bovine serum (FBS) or platelet lysate (PL). These 3D culture systems were analyzed in terms of their capability to maintain chondrocyte differentiation in vitro. This was achieved by evaluating cell morphology, immunohistochemistry $(\mathrm{IHC})$, gene expression of relevant cartilage markers (collagen type II, aggrecan, and Sox9), and specific markers of dedifferentiated phenotype (collagen type I, Runx2). The morphological, histochemical, immunohistochemical, and molecular results demonstrated that the 3D $\mathrm{CH}$ scaffold is sufficiently porous to be colonized by primary chondrocytes. Thereby, it provides an optimal environment for the colonization and synthetic activity of chondrocytes during a long culture period where a higher rate of dedifferentiation can be generally observed. Enrichment with hyaluronic acid provides an optimal microenvironment for a more stable maintenance of the chondrocyte phenotype. The use of 3D CH scaffolds causes a further increase in the gene expression of most relevant ECM components when PL is added as a substitute for FBS in the medium. This indicates that the latter system enables a better maintenance of the chondrocyte phenotype, thereby highlighting a fair balance between proliferation and differentiation.

Keywords: chitosan, platelet lysate, chondrocytes, cartilage, biomaterials, tissue engineering, hyaluronic acid

\section{INTRODUCTION}

Osteoarthritis $(\mathrm{OA})$ is one of the major challenges in joint pathology in both humans and animals. Once damaged, the cartilage has limited capability for repair due to its avascular nature and to the low metabolic index of chondrocytes. Cellular and molecular mechanisms that cause altered repair involve the loss of chondrocyte differentiation and cartilage homeostasis (1). In 
addition, fibrocartilaginous tissue is formed, with reduced mechanical capacity compared with native cartilage.

Tissue engineering is a potential field of regenerative medicine. It is based on the interaction of three main elements (a support biomaterial, growth factors, and cells) for the development of a biological substitute that can be used for replacement, restoration, or regeneration of damaged tissues and organs (2).

The use of live cells and biocompatible polymers represents an important technique for the repair of cartilage defects. This is primary considering that the seeding of chondrocytes onto these three-dimensional (3D) scaffolds is the main condition for maintaining chondrocyte differentiation and cartilage ECM synthesis $(3,4)$. The selected biomaterial sustaining chondrocyte cell growth must exhibit several characteristics in relation to the chemical and physical properties of the native cartilage $(5,6)$.

Accordingly, a porous polymeric scaffold provides a temporary substrate that guides and sustains cell proliferation, differentiation, and tissue growth. Moreover, a mechanically active scaffold plays an important role in the maintenance of structural integrity and delivery of signals that stimulate cell adhesion and synthesis. Studies have been carried out on horses to assess the suitability of chondrocyte transplantation for the repair of articular cartilage defects. A few of these verified that chondrocyte implantation into a biocompatible matrix can result in a promising therapeutic option for the treatment of cartilage defects $(7-11)$.

Among the suitable biomaterials for the maintenance of differentiated chondrocytes and for the delivery of cells into a tissue, chitosan $(\mathrm{CH})$ and hyaluronic acid (HA), are two polysaccharides that are widely utilized as scaffolds in articular cartilage regeneration (12).

$\mathrm{CH}$ has a structure like that of glycosaminoglycans (GAGs) of the extracellular matrix (ECM) of native cartilage $(13,14)$. Furthermore, it has been recommended as a good biomaterial for the growth and maintenance of chondrocytes in vitro $(8,15-18)$.

Hyaluronate is a GAG, natural component of cartilage ECM and of the synovial fluid of joints. In cartilage, HA links aggrecan monomers, to form large aggregating proteoglycans (LAPs); LAPs retain water and create an "internal swelling pressure" that counteracts compression forces in articular cartilage (19). HA also functions as an environmental cue to regulate cell behavior during embryonic development, healing processes, and inflammation (20).

In addition, in vitro and in vivo studies have shown that platelet-rich plasma (PRP) has positive effects on articular cartilage (21-26). In vivo, it has been reported that intra-articular injection of autologous PL aids in temporary management of OA of the distal interphalangeal joint in athletic horses (27) and significantly improves clinical scores of $\mathrm{OA}$ in human patients (28). In vitro studies have reported that PRP induces proliferation and synthesis of ECM components in chondrocytes (29-31), and chondrogenesis (32).

This effect is due to several growth factors that exert trophic effects on cartilage $(30,33-37)$. Platelet lysate (PL) is obtained from PRP by the release of growth factors from platelets through repeated freezing and thawing cycles. It has recently been studied as an alternative to fetal bovine serum (FBS) in culture (38-40).

The manufacturing of scaffolds and/or constructs through $3 \mathrm{D}$ printing has gained popularity in tissue engineering owing to its capability to develop complex formulations for cartilage regeneration (41-44).

Recently, the behavior of 3D-printed CH-based scaffolds was explored as a function of the post-printing gelation process, in terms of the capability to retain the 3D structure, water content, mechanical resistance, and surface/internal porosity, as well as the biocompatibility with fibroblasts as a skin-associated human cell line (45).

We propose that 3D-printed $\mathrm{CH}$-based scaffolds represent a suitable environment for chondrocyte culture in vitro and that its enrichment with HA could be helpful for the maintenance of chondrocyte phenotype. Moreover, the supplementation with PL could improve the phenotype stability of chondrocytes better then FBS, as observed in chondrocytes in adherent conditions $(39,46)$. In the present work, 3D-printed $\mathrm{CH}$ scaffold was prepared with HA and studied in terms of its capability to maintain chondrocyte differentiation in vitro in the presence of FBS or PL.

\section{MATERIALS AND METHODS \\ Preparation of 3D Chitosan Scaffolds}

Chitosan powder (ChitoClear ${ }^{\mathrm{TM}}$ TM4030, DD of 75\%; MW 50

$\mathrm{kDa}$, Primex Ehf, Iceland) was dispersed at the concentration of $6 \% \mathrm{w} / \mathrm{v}$ into a $0.02 \% \mathrm{w} / \mathrm{v}$ aqueous solution of sodium hyaluronate (HA) (Halien, High MW, ACME s.r.l., Cavriago, Italy, batch Ha16003), magnetically stirred until homogenization $(5 \mathrm{~s})$ and made up to volume dropwise with glacial acetic acid (Sigma-Aldrich) until a final concentration of $2 \% \mathrm{v} / \mathrm{v}$. Complete dissolution of chitosan was achieved after overnight magnetic stirring at $24^{\circ} \mathrm{C}$. D-(+)-raffinose pentahydrate (Sigma-Aldrich, USA) was added at a concentration of $290 \mathrm{mM}$ as viscosity agent (47) and dissolved by magnetic stirring. The same procedure was adopted to prepare the chitosan-based solution free of hyaluronic acid: in this case, dissolution of chitosan took place in a $2 \% \mathrm{v} / \mathrm{v}$ acetic acid solution in UltraPure water (Purelab Flex 1 system, ELGA Veolia) to which D-(+)-raffinose was added at $290 \mathrm{mM}$. Polymeric blends were stored at $4^{\circ} \mathrm{C}$ until use.

The CAD model for 3D printing of scaffolds was designed by means of Solidworks ${ }^{\mathrm{TM}}$ software (Dassault Systems, USA) by drawing a grid composed of overlapping parallel filaments set at a nominal distance of $200 \mu \mathrm{m}$. Total sizes of the object, formed by five layers, were also set, $1.5 \times 1.5 \times 0.1 \mathrm{~cm}$ (width/length/thickness). The file produced was then converted through the software Slic3r ${ }^{\mathrm{TM}}$ (RepRap) from the generated. stl format (STereo Lithography interface format) to the machine code (gcode format) readable by the in-house-built 3D printer. Briefly, the platform physically supporting the $3 \mathrm{D}$ construction consisted of a 0.6-mm-thick stainless-steel plate coated with a 0.6- $\mathrm{mm}$ chitosan or chitosan-HA film casted prior to printing, which was fixed on the Peltier cells of the 3D machinery and instantly frozen at temperature of $-18^{\circ} \mathrm{C}$ : this film constituted the base for the scaffold. Polymeric blends were loaded into 
5-ml syringes equipped with a blunt $26 \mathrm{G}$ needle (internal ø: $0.260 \mathrm{~mm}$ ), which were fixed on the machinery's robotic arms and connected to the pressure-assisted mechanical piston (extruder). Solutions were deposited by the extruding apparatus moving along $x$-, $y$-, and $z$-axis on the top of the base film, and instantly frozen at a constant temperature of $-18^{\circ} \mathrm{C}$ exploiting freeze deposition layer by layer to give shape to the polymeric blend to obtain the 3D object designed, according to a method recently described (48). At the end of each manufacturing process, frozen scaffolds underwent ionotropic gelation by exposure to saturated ammonia vapors for $1 \mathrm{~h}$ at ambient temperature, following the technique reported in a previous work dealing with the settlement of suitable gelation processes for 3D chitosan hydrogels (45). Scaffolds were then washed by immersion in $80 \mathrm{ml}$ of UltraPure water until neutral $\mathrm{pH}$ (four times for $10 \mathrm{~min}$ ) to eliminate ammonia residues and raffinose (47). Finally, scaffolds were punched round to fit into 24 -well plates, sterilized by immersion in $70 \% \mathrm{w} / \mathrm{v}$ ethanol, transferred to sterile phosphate buffered saline (PBS) and preserved at $4{ }^{\circ} \mathrm{C}$ until use.

The mechanical resistance of scaffolds obtained by different gelation media was compared on 20-layer scaffolds of $5 \times$ $1.5 \mathrm{~cm}$. Hydrogels at the maximum swollen state were tested. Thickness was determined as a mean of six measurements of the scaffold performed with a digital micrometer (Mitutoyo, Japan). Each scaffold was fixed on a tensile tester (AG M1 Acquati, Italy) loaded with a 5-daN cell. Force and time signals were digitalized by means of a PowerLab 400 board and recorded with Scope 3.5 software. Elongation at break (\% strain) and Young's modulus were determined from the relevant stress-strain curves, taking into consideration the linear portion and normalized by thickness (45).

\section{Preparation of PL}

The donor horses were referred to the Veterinary Teaching Hospital of the University of Parma and were examined by a veterinarian to assess their clinical history and to exclude systemic and hematological diseases. Blood was collected and placed into tubes supplemented with sodium citrate $(0.38 \%$ final concentration). The citrated blood was centrifuged in a standard laboratory centrifuge (swinging rotor) for $20 \mathrm{~min}$ at $180 \times g$. Afterwards, the portion of plasma enriched with platelets was transferred to another tube and platelets were pelleted in a second centrifugation step for $15 \mathrm{~min}$ at $900 \times g$. The pellet was resuspended so as to obtain a concentration of $1 \times 10^{9}$ platelets per $1 \mathrm{ml}$. The PRP was subjected to a double freezing cycle at $-80^{\circ} \mathrm{C}$ and thawing at $-37^{\circ} \mathrm{C}$. To remove platelet remnants derived from freezing-thawing cycles, a further centrifugation was performed (Microfuge 22R Centrifuge) for $20 \mathrm{~min}$ at 11,000 $\times g$. PL supernatant was collected and stored at $-80^{\circ} \mathrm{C}$ until use (39).

\section{Cell Cultures}

Horses ranging from 5 to 8 years old and farmed for human consumption were slaughtered and the metacarpophalangeal and metatarsophalangeal joints were immediately delivered to our laboratory for collection of cartilage. Before cartilage harvesting, joints were carefully examined and those with macroscopic lesions related to overt OA or with evidence of synovitis were excluded from the study. The articular cartilage was obtained from three joints/experiment; chondrocytes were isolated separately from each cartilage and then checked for viability and the samples with viability $<95 \%$ were excluded. Then, three samples were pooled for each experiment and three experiments were done, with three replications/experiment.

Chondrocytes were isolated from tissue following a protocol previously described (39). Briefly, cartilage was finely diced under sterile conditions and then washed several times in PBS. After pre-incubation in $0.1 \%$ pronase (Sigma) solution for $1 \mathrm{~h}$ at $37^{\circ} \mathrm{C}$, the tissue was treated with $0.2 \%$ collagenase type IA (Sigma) in D-MEM (4.5 g/L glucose; $25 \mathrm{mM}$ Hepes) for $2 \mathrm{~h}$ at $37^{\circ} \mathrm{C}$. The digested material was filtered through $100-\mu \mathrm{m}$ and 20 $\mu \mathrm{m}$ nylon filters and the cellular suspension was centrifuged at $1,800 \mathrm{rpm}$ for $10 \mathrm{~min}$. The supernatant was discarded, and the pellet was washed several times with D-MEM containing $10 \%$ fetal calf serum (FBS), $100 \mathrm{U} / \mathrm{ml}$ penicillin and $0.1 \mathrm{mg} / \mathrm{ml}$ streptomycin. The number of chondrocytes was determined using a hemocytometer and the cell viability (never <95\%) was assessed by trypan blue $(0.1 \%)$ exclusion. The chondrocytes were seeded into $3 \mathrm{D}$ chitosan scaffolds $(\mathrm{CH})$ with or without hyaluronic acid $(\mathrm{CH}+\mathrm{HA})$ at a density of $8 \times 10^{5}$ cells/scaffold.

The culturing medium contained $10 \%$ FBS or $5 \% \mathrm{PL}$ or nothing (-FBS/-PL). All cultures were incubated at $37^{\circ} \mathrm{C}$ in a humidified atmosphere of $5 \% \mathrm{CO}_{2}$ in air for the time specified for each single experiment and the medium was exchanged biweekly.

\section{Histology}

The adhesion, colonization, and morphological characteristics of the cells in 3D systems was histologically evaluated after 2 weeks and 4 weeks of culture.

At the end of experimental time, scaffolds were fixed with $4 \%$ paraformaldehyde (PFA) in PBS for $40 \mathrm{~min}$ at room temperature. After fixation, the scaffolds were washed to eliminate any residues of PFA and then pre-embedded in $100 \mu \mathrm{l}$ of $2 \%$ agarose solution in distilled water to preserve the $3 \mathrm{D}$ culture and facilitate scaffold handling. The samples were then dehydrated in increasing alcohol concentrations, clarified in xylene, and paraffin embedded. Histological sections $5 \mu \mathrm{m}$ thick were obtained using a rotary microtome (Slee Cut 6062, Slee Medical, Mainz, Germany). Sections were stained with hematoxylin-eosin (H\&E) and Masson's trichrome (with Aniline-Blue). Microphotographs were acquired with Nikon Digital Sight System.

\section{Immunohistochemistry}

Immunohistochemical analysis was performed at 2 and 4 weeks of culture in order to determine the positivity of ECM to collagen type II. Sections were treated with $2 \%$ Hyaluronidase (Sigma) in PBS for $30 \mathrm{~min}$ at $37^{\circ} \mathrm{C}$. Endogenous peroxidases were quenched with $3 \% \mathrm{H}_{2} \mathrm{O}_{2}$ for $12 \mathrm{~min}$ at room temperature and then aspecific antigens were blocked with $1 \%$ bovine serum albumin (BSA) (Sigma) in PBS for $1 \mathrm{~h}$ at room temperature. The slides were then incubated overnight at a $4{ }^{\circ} \mathrm{C}$ with primary monoclonal antibody anti-collagen II (1:100) (orb 156420; Byorbit). Then, secondary biotinylated anti-rabbit antibody (BA-100, Vector Laboratories) 
was applied for $1 \mathrm{~h}$ at room temperature. Slides were incubated with an ABC Kit (PK7800, Vector laboratories), and then with 3,3/-diaminobenzidine (DAB) for $3 \mathrm{~min}$, counterstained with Mayer's hematoxylin and then dehydrated in ascending scale of alcohols and permanently mounted.

Slides were then digitalized and collagen type II was quantified using NIS-elements AR (Nikon, Japan) on three (per case) digital images at $10 \times$ magnification. The total number of cells was obtained identifying the nuclei through a nuclear thresholdbased mask; this mask was converted into regions of interest (ROIs) (each nucleus represents a single counting ROI). In order to include cytoplasm and pericellular space, the mask was expanded for three layers through a mathematical morphologythickening function (NIS-element AR, Nikon, Japan). The number of positive cells [( $\mathrm{N}$ of collagen Type II positive cells/total number of cells) $* 100$ ] was obtained overlaying the ROIs with a threshold based on collagen type II signal and considering only ROIs with positive signaling.

\section{Scanning Electron Microscopy}

The scanning electron microscopy (SEM) of cells grown on chitosan scaffolds was performed after 2 weeks and 4 weeks of culture $(49,50)$. Scaffolds seeded with cells were fixed at each selected time point with $2.5 \%$ glutaraldehyde in $0.1 \mathrm{M}$ sodium cacodylate buffer $(\mathrm{pH} 7.3)$ for $2 \mathrm{~h}$ at $4^{\circ} \mathrm{C}$. They were then dehydrated through a series of increasing grades of ethanol (from $50 \% \mathrm{v}$ until absolute) and then critical point dried with liquid carbon dioxide (CPD 030 Baltec, Wallruf, Germany). Specimens were then sputter-coated (Balzers device) with gold-palladium (Plano, Germany) using a SCD 040 coating device (Balzer Union, Wallruf, Germany). The samples were observed using a Philips 501 SEM scanning electron microscope at an accelerating voltage of $5 \mathrm{kV}$. The chitosan scaffolds without cells were used as control samples (blank).

\section{Gene Expression of Differentiation Markers Total RNA Extraction}

Total RNA of each sample was extracted using combined protocol with TRIreagent (Thermo Fisher Scientific) and PureLink $^{\circledR}$ RNA Micro Kit (Thermo Fisher Scientific), according to the manufacturer's instructions. Scaffolds containing cells were dissolved into TRIreagent and then the RNA was extracted according to the datasheet of PureLink ${ }^{\circledR}$ RNA Micro Kit. All RNA samples were DNasetreated during protocol execution. Purity and concentration were assessed by UV spectrophotometry at 260/280 and $260 \mathrm{~nm}$, respectively (BioSpectrometer, Eppendorf, Hamburg, Germany). RNA integrity and quality were assessed by using an Agilent Bioanalyzer 2100 and RNA 6000 Labchip kit (Agilent Technologies, Santa Clara, CA, USA).

\section{Reverse Transcription (RT)}

Total RNA $(1 \mu \mathrm{g} / 20 \mu \mathrm{l})$ was reverse-transcribed using a High-capacity cDNA Reverse Transcription kit (Applied Biosystems-Life Technologies, Carlsbad, CA, USA) according to the manufacturer's instructions, under the following thermal conditions performed by using a StepOne thermocycler (Applied
Biosystems, StepOne): $10 \mathrm{~min}$ at $25^{\circ} \mathrm{C}, 120 \mathrm{~min}$ at $37^{\circ} \mathrm{C}$, followed by $5 \mathrm{~min}$ at $85^{\circ} \mathrm{C}$. All cDNA samples were stored at $-20^{\circ} \mathrm{C}$ until PCR was performed.

\section{Quantification of mRNA by Real-Time PCR (qPCR)}

cDNA concentration was assessed by UV spectrophotometry (BioSpectrometer, Eppendorf, Hamburg, Germany) and $5 \mathrm{ng}$ of each sample was used as a template for real-time quantitative PCR (qPCR) performed by using a StepOne thermocycler (Applied Biosystems, StepOne software v. 2.1). The cDNA (5 $\mathrm{ng} / 20 \mu \mathrm{l}$ ) was amplified in triplicate with Power Up SYBR Green Master Mix (Applied Biosystems-Life Technologies, Carlsbad, CA, USA) along with specific sets of primers at 300 or $500 \mathrm{nM}$. The primers were designed based on published gene sequences or by using Primer Express ${ }^{\circledR}$ software package (Applied Biosystems) to create oligonucleotides with similar melting temperatures and minimal self-complementary, and purchased from Eurofins Genomics (Ebersberg, Germany). Details of each primer set for detection of gene expression are reported in Table 1 (39).

The reference gene GAPDH (glyceraldehyde-3-phosphate dehydrogenase) was selected as an endogenous control according to minimal intra-/inter-assay variation. Samples were kept at $95^{\circ} \mathrm{C}$ for $20 \mathrm{~s}$ (hold step) to allow DNA-polymerase activation and then subjected to 40 cycles consisting of a denaturation step at $95^{\circ} \mathrm{C}$ for $3 \mathrm{~s}$ followed by an annealing/extension step at $60^{\circ} \mathrm{C}$ for $30 \mathrm{~s}$. Fluorescence due to SYBR Green I incorporation was acquired at the end of the extension step. A no-RT control and a no-template control (NTC) were included in each experiment. A melting curve analysis for specific amplification control was performed (from 60 to $95^{\circ} \mathrm{C}$ ) at the end of the amplification cycles. NTC controls were assumed as negative and reliable if the

TABLE 1 | Primer sequences used for real-time polymerase chain reaction.

\begin{tabular}{|c|c|c|}
\hline Gene & Primer sequences & $\begin{array}{c}\text { Primer } \\
\text { concentration } \\
\text { (nM) }\end{array}$ \\
\hline \multirow[t]{2}{*}{ GAPDH } & FWD: CAAGGCTGTGGGCAAGGT & 300 \\
\hline & REV: GGAAGGCCATGCCAGTGA & 300 \\
\hline \multirow[t]{2}{*}{ COL1A1 } & FWD: AGAAGAAGACATCCCAGCAGTCA & 500 \\
\hline & REV: CAGGGCTCGGGTITCCATA & 500 \\
\hline \multirow[t]{2}{*}{ COL2A1 } & FWD: CTGGTGATGATGGTGAAG & 300 \\
\hline & REV: GTAACCTCTGTGACCTITG & 300 \\
\hline \multirow[t]{2}{*}{ ACAN } & FWD: GACCACTITACTCTTGGCGTITG & 500 \\
\hline & REV: GTCAGGGTCTGAAACGTCTACTGA & 500 \\
\hline \multirow[t]{2}{*}{ VCAN } & FWD: GCAACCCATGCACTACATAAAGTC & 500 \\
\hline & REV: TCCAGAGAGGGAGCCCTTAAC & 500 \\
\hline \multirow[t]{2}{*}{ SOX9 } & FWD: CAGGTGCTCAAGGGCTACGA & 300 \\
\hline & REV: GACGTGAGGCTTGTTCTTGCT & 300 \\
\hline \multirow[t]{2}{*}{$R \cup N \times 2$} & FWD: CCCGTGGCCTTCAAAGTG & 300 \\
\hline & REV: TGACAGTAACCACAGTCCCATCTG & 300 \\
\hline
\end{tabular}

GAPDH, glyceraldehyde-3-phosphate dehydrogenase; COL1A1, Collagen type I; COL2A1, Collagen type II; ACAN, Aggrecan; VCAN, Versican; SOX9, Transcription factor SOX-9; RUNX2, Runt-related transcription factor 2. 

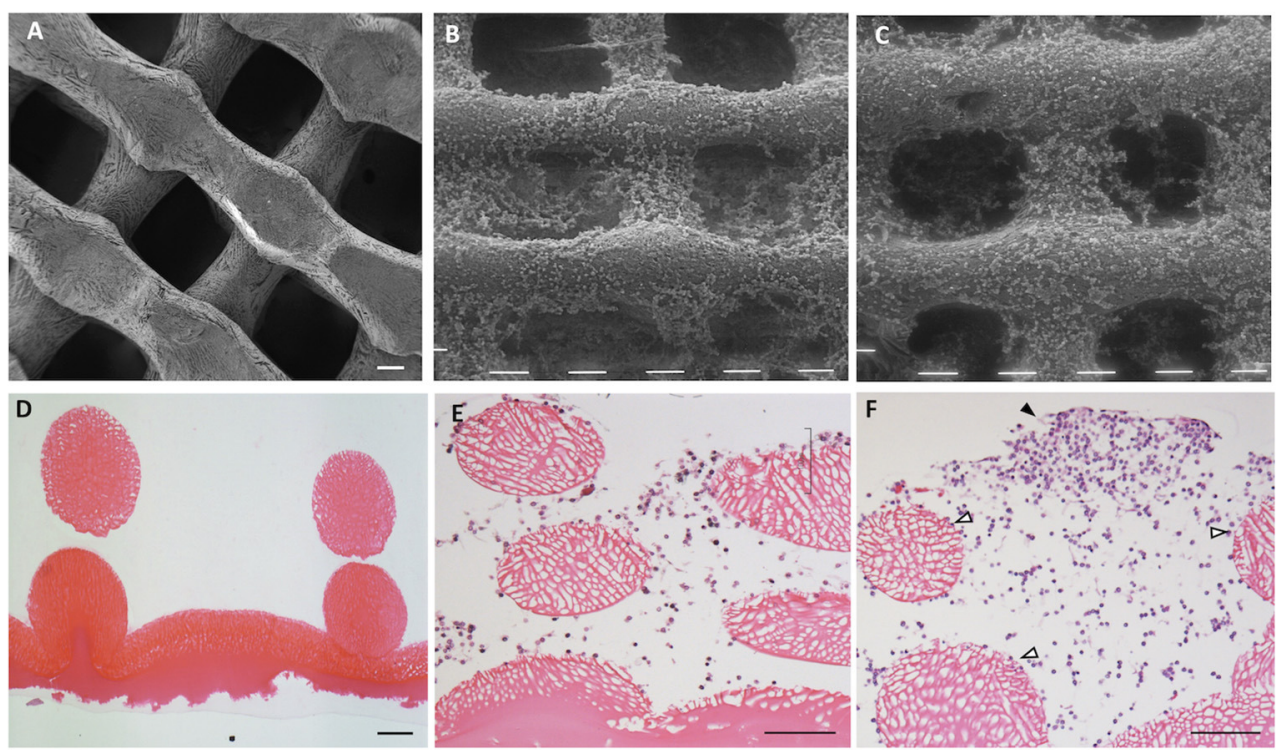

FIGURE 1 | Chitosan scaffold at scanning electron microscopy (SEM) (A-C) and at light microscopy (hematoxylin-eosin staining; D-F). The structure of chitosan scaffold without cells $(\mathbf{A}, \mathbf{D})$. Chitosan scaffold $(\mathbf{B}, \mathbf{E})$ and chitosan scaffold functionalized with hyaluronic acid (HA) (C,F) with chondrocytes after 2 weeks of culture. Black tips: cell cluster; white tips: single cells. Scale bar $=100 \mu \mathrm{m}$.

quantification cycle $(\mathrm{Cq})$ was $\geq 35$. Data were analyzed according to the $2^{-\Delta \Delta \mathrm{Ct}}$ method $(51,52)$ in which expression levels of each gene are normalized to the GAPDH cDNA amount and expressed as relative quantities.

\section{Statistical Analysis}

The experimental results were presented as the mean \pm SD. In each experiment, each treatment was performed with three replicate culture wells. Statistical differences were calculated with multifactorial ANOVA using the SPSS 21.0 for Window (IBM ${ }^{\circledR}$ SPSS ${ }^{\circledR}$ Statistics, IBM, New York, USA). When significant differences were found, means were compared by Scheffe's $F$ test.

\section{RESULTS}

\section{Scaffold Structure and Cell Colonization}

The structure of the 3D CH scaffold consisted of an upper part of a regular network of $\mathrm{CH}$ fibers forming pores of approximately $200 \mu \mathrm{m}$ (Figure 1A) and a basal layer of $\mathrm{CH}$ film (Figure 1D) to hold cells and prevent their adhesion to the plastic plate.

Mechanical resistance was tested for both types of scaffold, resulting in $128 \mathrm{kPa} \pm 21 \mathrm{kPa}$ (\% strain at rupture $52.3 \pm 5.3 \%$ ) for the chitosan scaffold and $156 \mathrm{kPa} \pm 25 \mathrm{kPa}$ (\% strain at rupture $50.6 \pm 10.9 \%$ ) for the chitosan + hyaluronic acid scaffold, without any statistically significant difference. Furthermore, the scaffolds retained their structure for up to 6 months when stored in water or saline solution: no statistically significant alteration of the structure was observed. When immersed in culture media, all scaffolds retained their original dimensions for up to 21 days.

After 2 weeks of culture in both types of scaffolds (Figures 1B,C), chondrocytes colonized the scaffold reticulate. A few cells settled in the spaces within the reticulate, whereas others adhered to the surface of fibers of scaffold.
The chondrocytes penetrated inside the 3D structure and colonized the spaces between the fibers (Figure 1E). The chondrocytes used the spaces as niches for proliferation and growth by organizing in clusters, which became larger during culture (Figure 1F, black arrowhead) or remained as single cells adhering to the surface of the scaffold fibers (Figure 1F, white arrowhead).

\section{Scanning Electron Microscopy}

After 2 weeks, the chondrocytes cultured with FBS colonized the pores of the scaffold's reticulate texture. However, these appeared with an evident double cell morphology, both roundish cells and fibroblast-like cells (Figure 2A, white arrowheads and white arrows). When the scaffold was prepared with HA, roundish chondrocytes became predominant and a little production of filamentous matrix became evident (Figure 2B, white stars). In the presence of $\mathrm{PL}$, the chondrocytes had a roundish morphology, and the presence of filaments compatible with matrix production was apparent in both types of scaffolds (Figures 2C,D, white stars).

After 4 weeks of culture with FBS, the chondrocytes colonized the pores of the scaffold's reticulate texture. Moreover, these appeared to be more numerous in $\mathrm{CH}$ scaffolds both with and without HA enrichment, compared with that for PL treatment. In the FBS condition, the chondrocytes maintained the double morphological features, and a few fibroblast-like cells became evident in the scaffold prepared with HA (Figure 3B, white arrows). Furthermore, the cells began to produce a few matrix filaments (Figures 3A,B, white stars).

After 4 weeks of PL supplementation, the cell population increased and the chondrocytes that covered the scaffold texture were more numerous, compared with the scenario after 2 weeks. In this culture condition, the chondrocytes showed a 

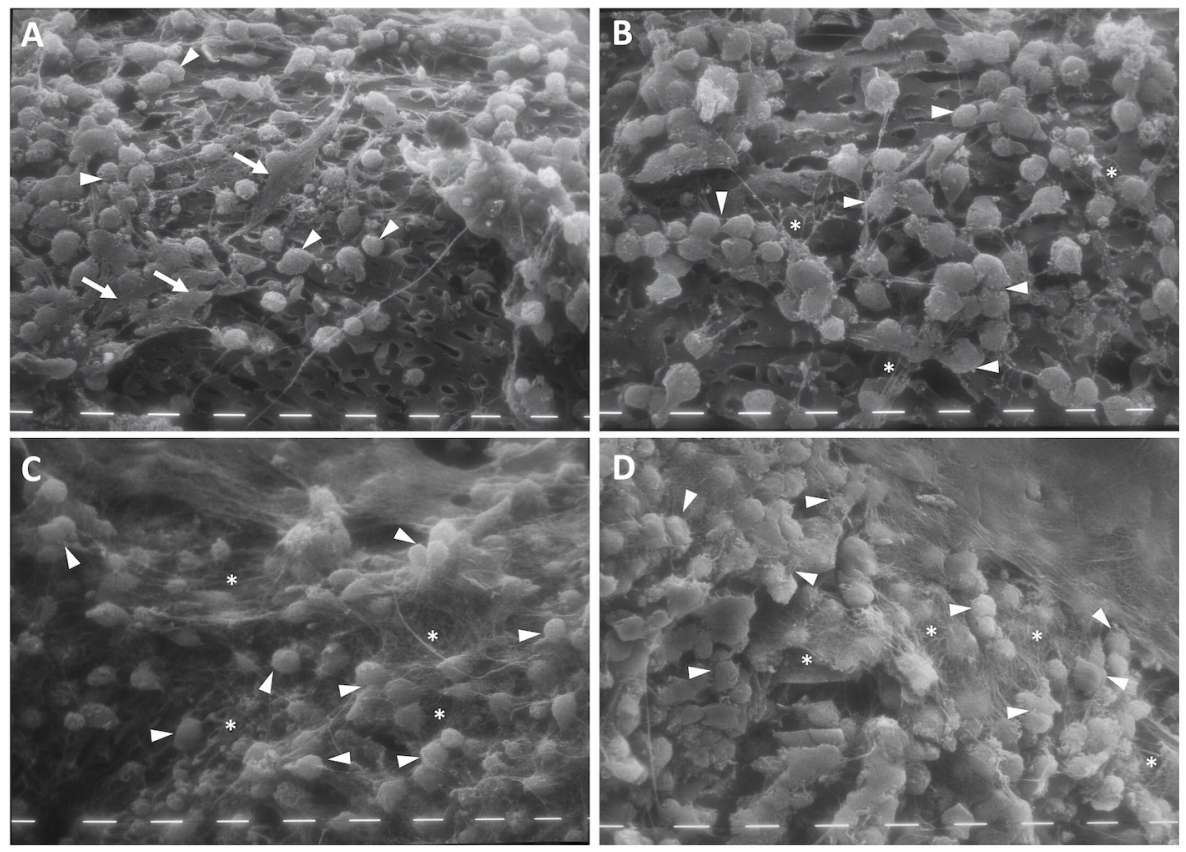

FIGURE 2 | Scanning electron microscopy (SEM) of chitosan scaffold (A,C) and chitosan scaffold prepared with hyaluronic acid (HA) (B,D) with chondrocytes after 2 weeks of culture with FBS (A,B) and PL (C,D). White arrows: fibroblast-like cells; white tips: round cells; white stars: filaments of matrix. Scale bar $=10 \mu \mathrm{m}$.
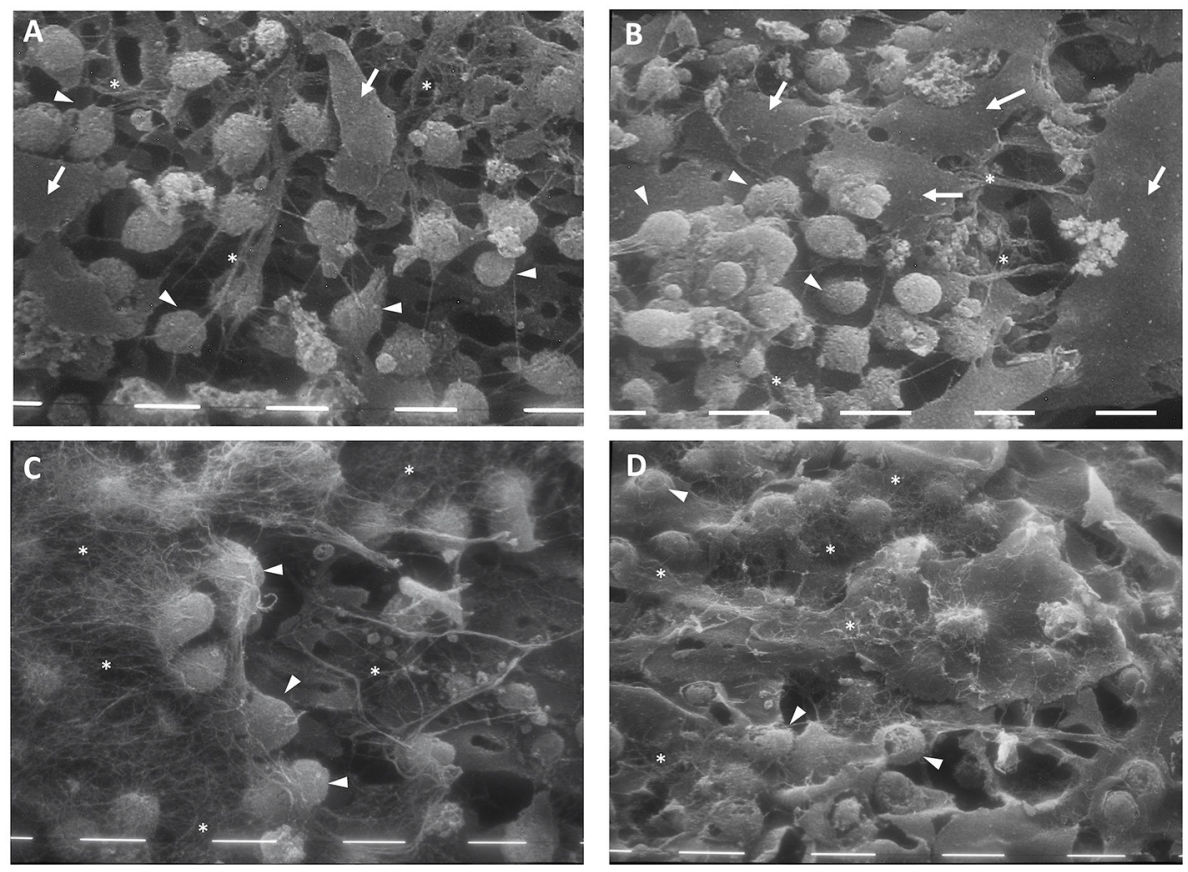

FIGURE 3 | Scanning electron microscopy (SEM) of chitosan scaffold $(\mathbf{A}, \mathbf{C})$ and chitosan scaffold prepared with hyaluronic acid $(\mathrm{HA})(\mathbf{B}, \mathbf{D})$ with chondrocytes after 4 weeks of culture with FBS $(\mathbf{A}, \mathbf{B})$ and PL $(\mathbf{C}, \mathbf{D})$. White arrows: fibroblast-like cells; white tips: round cells; white stars: filaments of matrix. Scale bar $=10 \mu \mathrm{m}$.

round morphology and a significant amount of filamentous matrix production (Figures $\mathbf{3 C}, \mathbf{D}$, white stars) in both types of scaffolds.

\section{Histology}

The production of ECM by the chondrocytes was evaluated using Masson's trichrome stain. It highlighted the collagen-based ECM 


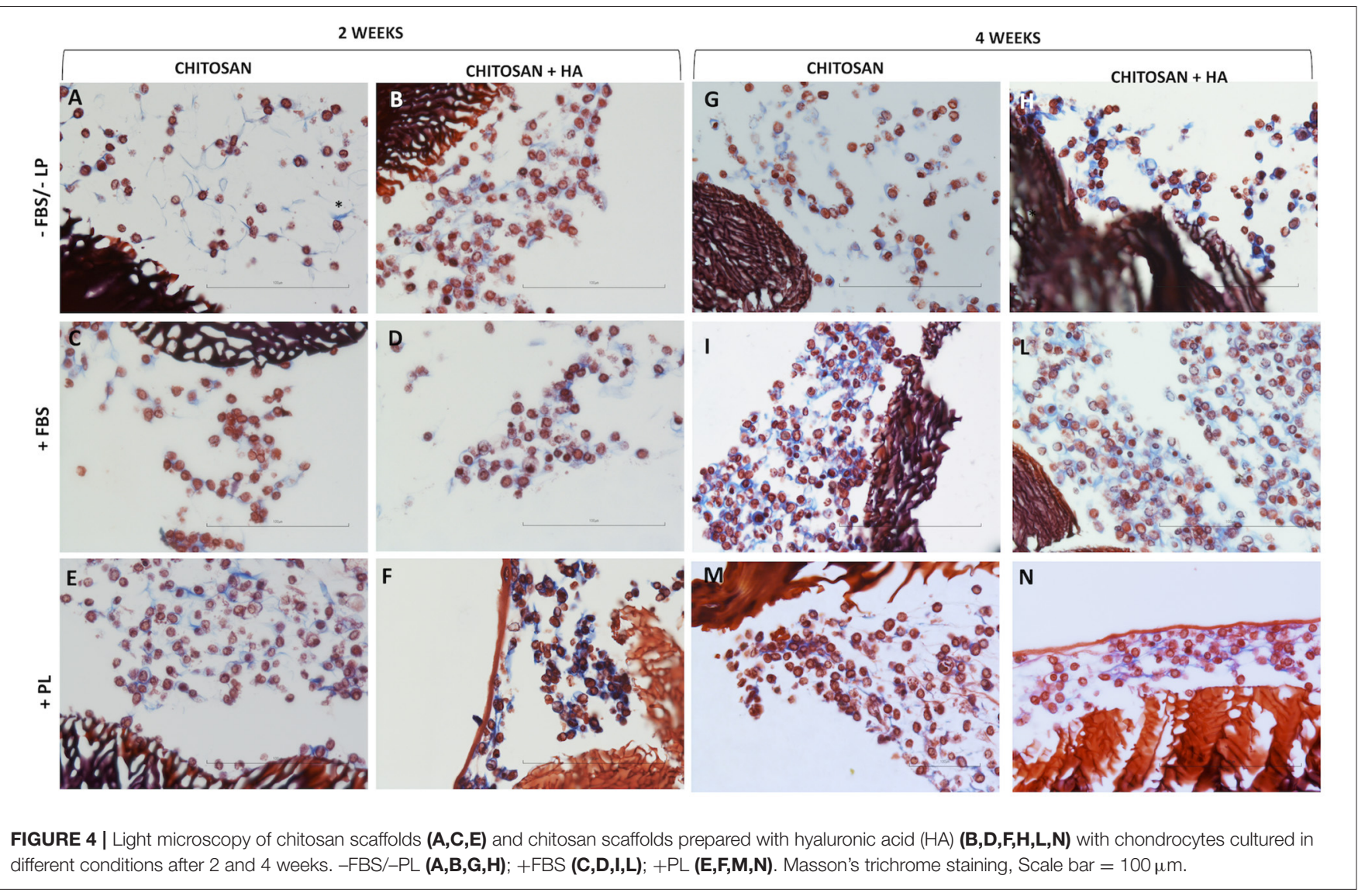

in blue, whereas the scaffold structure and cells were stained in dark red.

After 2 weeks of culture, matrix production was detected under all the conditions (Figure 4). However, this was more evident in the $\mathrm{CH}$ scaffolds with $\mathrm{HA}$ than in those without $\mathrm{HA}$, even in the absence of FBS/PL supplementation (Figure 4B). Furthermore, the presence of PL increased matrix production in both types of scaffolds (Figures 4E,F).

After 4 weeks of culture, the cells seeded on both types of scaffolds (Figure 4, right panel) continued to present a roundish and regular morphology comparable to that observed at 2 weeks. However, higher cell density was observed in certain areas of the scaffolds in the presence of FBS and PL (Figures 4I,L-N).

The matrix production was increased compared with that at 2 weeks under all the conditions. This was particularly so in the $\mathrm{CH}$ scaffolds with $\mathrm{HA}$ without FBS/PL supplementation (Figure 4H).

\section{Immunohistochemistry}

Collagen type II was used as a marker of chondrocyte ECM production. The expression of collagen type II after 2 weeks of culture (Figure 5, left panel) was low in the scaffolds without HA under all the tested culturing conditions (Figures 5A,C,E,O). A marginal more evident collagen II positivity was observed only in the PL supplementation condition. Rather, $\mathrm{CH}$ scaffolds with $\mathrm{HA}$ showed ECM production characterized by expression of collagen type II, particularly in FBS and PL supplementation conditions (Figures 5D,F,O).

After 4 weeks (Figure 5, right panel), collagen type II positivity was also evident in the ECM of the $\mathrm{CH}$ scaffolds without HA (Figures 5I,M,O) and remained higher in the $\mathrm{CH}$ scaffold with $\mathrm{HA}$ (Figures $\mathbf{5 H}, \mathbf{I}, \mathbf{N}, \mathbf{O}$ ). Without FBS/PL supplementation, the collagen type II expression remained at baseline (Figures 5G,H,O).

\section{Gene Expression}

\section{Gene Expression of Col1, Col2, ACAN, and VCAN}

The gene expression of collagen type I (Figure 6) increased significantly from second to fourth week of culture only in the presence of FBS, particularly for chitosan scaffolds without HA. Moreover, after 4 weeks, the presence of PL reduced the expression of Coll with respect to the other conditions. Reduction was significantly only when compared to FBS.

Molecular analysis (Figure 6) revealed a constantly higher expression of collagen type II when PL was added, compared with other culture conditions (-FBS/-PL and +FBS), followed by a less pronounced induction of transcription in the presence of FBS. In the FBS/PL-free condition, collagen type II expression was generally lower. These differences were not significant in the scaffolds without HA at 2 weeks.

Furthermore, in the presence of PL, the expression of collagen type II was increased in scaffolds with HA compared to scaffolds 


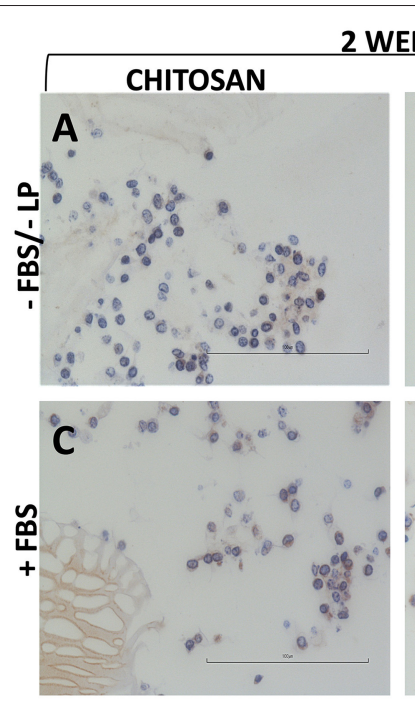

\section{WEEKS}
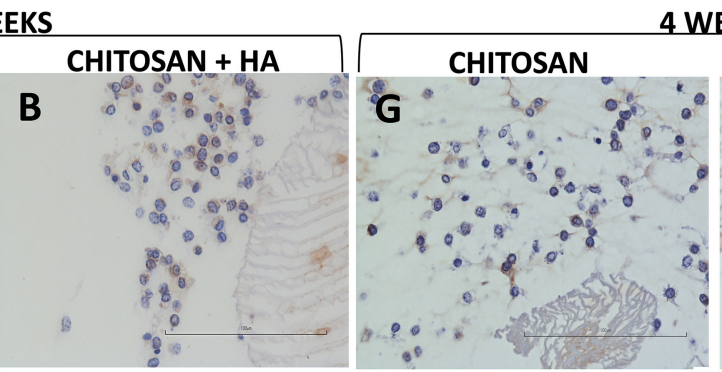

\section{WEEKS}
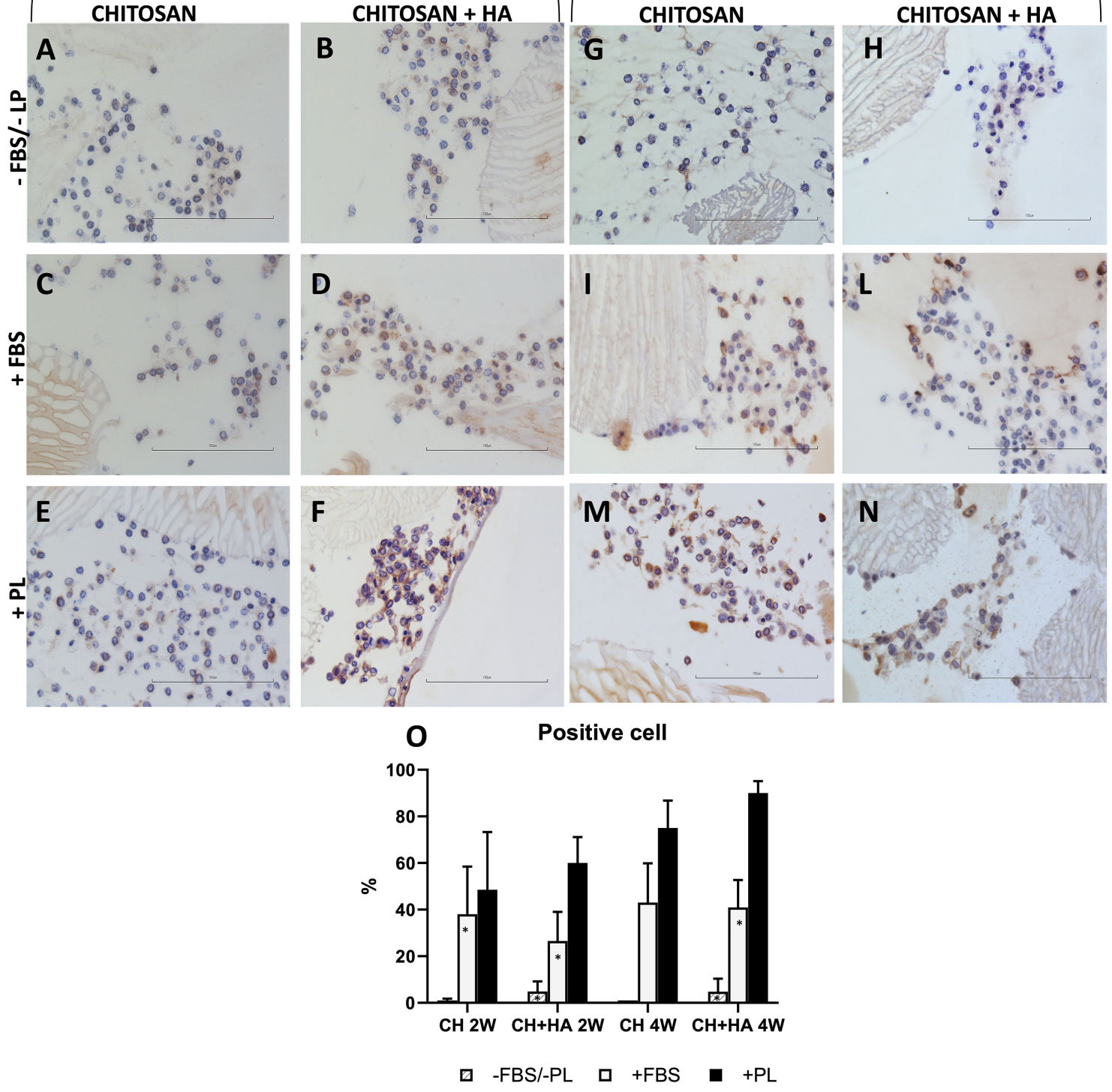

FIGURE 5 | Immunohistochemical stain for collagen type II in chitosan scaffolds (A,C,E,G,I,M) and chitosan scaffolds prepared with hyaluronic acid (HA) (B,D,F,H,L,N) with chondrocytes cultured in different conditions after 2 and 4 weeks. -FBS/-PL (A,B,G,H); +FBS (C,D,I,L); +PL (E,F,M,N). Scale bar = 100 $\mu$ m. (O) Quantification of Collagen type II expressed as percentage of positive cell. Statistical analysis: asterisk indicate significant differences versus $\mathrm{PL}\left({ }^{*} P<0.05, n=6\right)$.

without HA at 2 and 4 weeks of culture. Regarding aggrecan (Figure 6), the presence of PL significantly increased ACAN gene expression in all the conditions in comparison to that FBS/PL-free and with FBS. Furthermore, when PL was added, the gene expression of $A C A N$ increased, in the scaffolds with HA compared to scaffolds without HA at both times, and also increased between the second and fourth weeks in both the types of scaffolds.

After 2 and 4 weeks of culture, the gene expression of VCAN (Figure 6) significantly increased when PL was added compared to FBS and -FBS/-PL conditions in all types of scaffold, but only at 2 weeks in the scaffold with HA did FBS produce an increase comparable to PL. The gene expression of VCAN at 4 weeks increased only with PL in each type of scaffold, compared to 2 weeks.

\section{Gene Expression of Sox9 and Runx2}

A significant increase in Sox 9 (Figure 7) was observed in scaffolds with HA in the presence of PL after 4 weeks of culture. Furthermore, at 4 weeks, the presence of PL in scaffolds with HA significantly increased Sox 9 gene expression with respect to culture conditions without FBS/PL or with FBS.

Conversely, in scaffolds without HA and with FBS. Sox9 gene expression was reduced at 4 weeks compared with that after 2 weeks, and Runx2 (Figure 7) showed increased expression in both scaffolds with and without HA at 2 and 4 weeks only in 

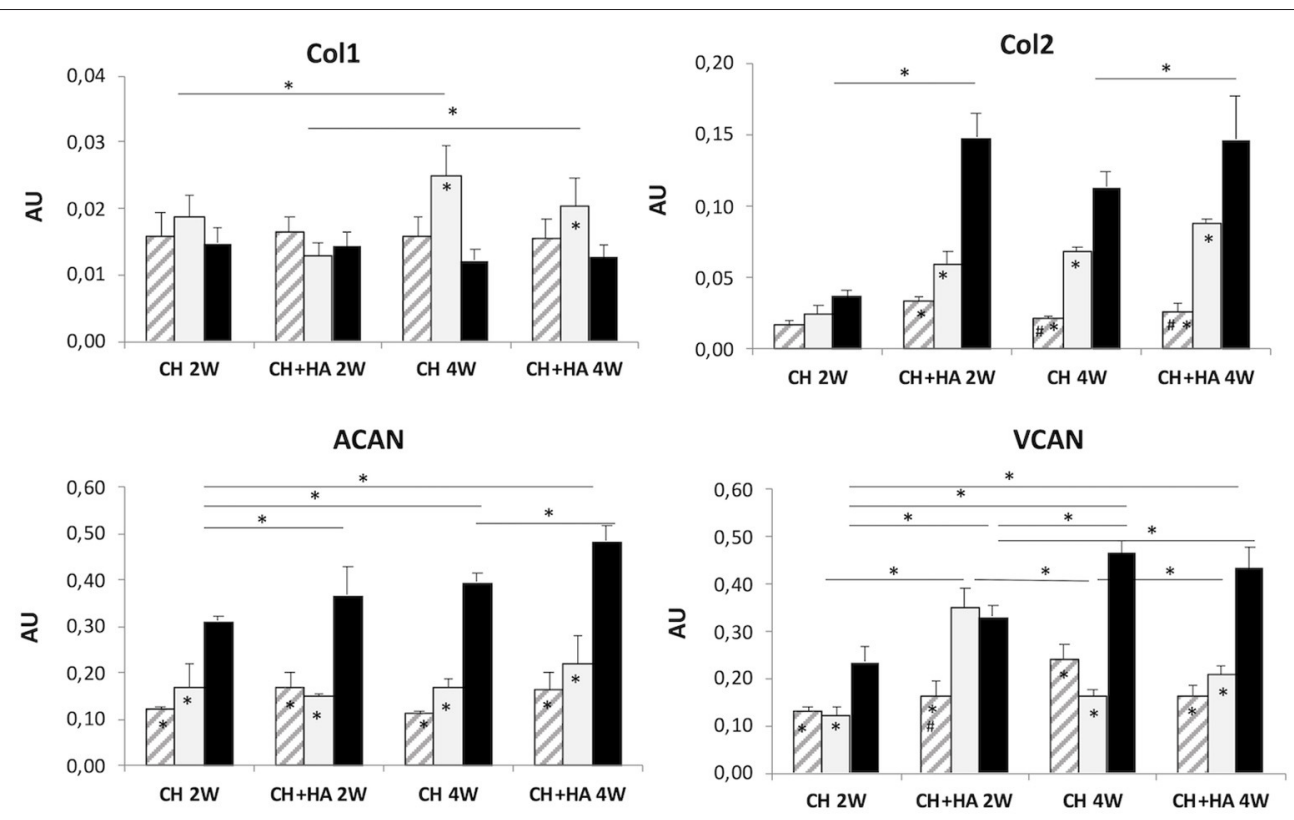

$\square-F B S /-P L \quad \square+F B S \quad \square+P L$

FIGURE 6 | Gene expression of collagen type I, collagen type II, aggrecan, and versican in chondrocytes cultured in chitosan scaffolds (CH) and chitosan scaffolds prepared with hyaluronic acid $(\mathrm{CH}+\mathrm{HA})$ after 2 and 4 weeks in different conditions (-FBS/-PL, +FBS, +PL). Statistical analysis: asterisks above the horizontal lines indicate significant differences of condition during time and among materials $\left({ }^{*} P<0.05\right)$. Within each material, asterisk indicates significant differences vs. PL and hashtag (\#) indicates significant differences vs. FBS $(n=9)$.

SOX9

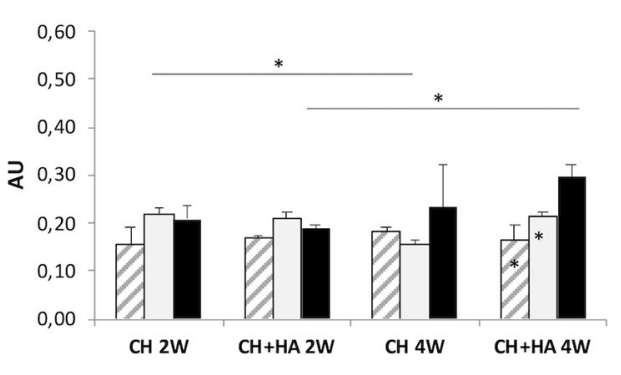

曰-FBS/-PL
RUNX2

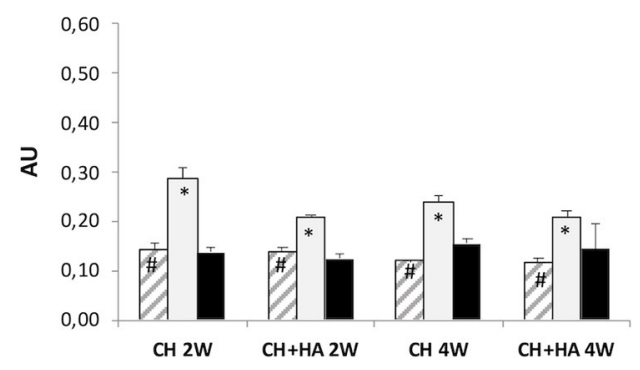

$\square+\mathrm{FBS}$

$\square+\mathrm{PL}$

FIGURE 7 | Gene expression of Sox9 and Runx2 in chondrocytes cultured in chitosan scaffolds $(\mathrm{CH})$ and chitosan scaffolds prepared with hyaluronic acid $(\mathrm{CH}+\mathrm{HA})$ after 2 and 4 weeks in different conditions (-FBS/-PL, +FBS, +PL). Statistical analysis: asterisks above the horizontal lines indicate significant differences of condition during time and among materials $\left({ }^{\star} P<0.05\right)$. Within each material, asterisk indicates significant differences vs. PL and hashtag (\#) indicates significant differences vs. $\operatorname{FBS}(n=9)$.

the presence of FBS, compared with that in the other two culture conditions (without FBS/PL and with PL).

\section{DISCUSSION}

Current opinion on tissue engineering approaches is that better in vivo repair can be achieved by combining cells (differentiated cells or MSC) into 3D biomaterial scaffolds made from natural and synthetic polymers with the addition of biological factors or molecules that control or guide cell differentiation (53).

The main role of the scaffold is to support cell colonization, migration, growth, and differentiation for the development and integration of the desired tissue (54). 3D printing has gained popularity in tissue engineering owing to its capability to 
develop scaffolds with spatial variation in cell distribution or in mechanical properties, and scaffolds built with multiple materials for the cultivation of complex tissues like cartilage $(41,55)$.

In the present study, the behavior of differentiated chondrocytes (adult horse articular chondrocytes) when cultured in $\mathrm{CH}$-based 3D-printed scaffolds prepared by the method described by Bergonzi (45) was evaluated in terms of their capability to maintain chondrocyte differentiation in vitro.

$\mathrm{CH}$ hydrogels have demonstrated good capacity to support chondrocyte colonization, vitality, and growth over time in culture (55). This is due to the ability of $\mathrm{CH}$ scaffolds to retain a good amount of water and thereby resemble native cartilage, where the water content plays a critical role in the biology and mechanical response of the tissue. An appropriate porosity is a critical characteristic to be considered. A scaffold designed for cartilage tissue engineering must be highly porous to provide a large area for uniform distribution of cells and have a pore size that promotes cell adhesion, cell proliferation, and ECM production (56-58).

In our study, 3D-printed $\mathrm{CH}$ scaffolds prepared in saturated $\mathrm{NH}_{3}$ gas showed pores having a mean size distribution of $200 \mu \mathrm{m}$ (45). This porosity demonstrated a good trade-off in terms of cell density and ECM synthesis. It is considered that for successful application, the pore sizes of $100 \mathrm{~mm}$ (59) or between 100 and $300 \mu \mathrm{m}$ can optimize cellular seeding and differentiation while facilitating the inflow and outflow of culture medium and can promote cell nourishment and waste dispersion (60).

$\mathrm{HA}$ is a fundamental component of cartilage tissue matrix and its addition to the $\mathrm{CH}$ scaffold favored colonization $(15,61)$. In our study, SEM analysis showed that chondrocytes penetrated inside the $3 \mathrm{D}$ structure and colonized the spaces between the fibers. Some cells organized in clusters while others adhered to the surface of scaffold fibers. The chondrocytes cultured with FBS showed evident twofold cell morphology (roundish and fibroblast-like); the roundish morphology was predominant in $\mathrm{CH}$ scaffold with $\mathrm{HA}$. In both types of scaffolds, the supplementation with PL showed coupled roundish morphology with a significant amount of filamentous matrix production.

The production of ECM, evaluated using both Masson's trichrome stain and immunostaining for collagen type II, was more abundant in $\mathrm{CH}$ scaffolds with $\mathrm{HA}$ than in those without HA, particularly when PL was used in alternative to FBS.

Analysis at the molecular level revealed that chondrocytes cultured in $3 \mathrm{D}$ conditions maintained phenotypic stability, even though significant differences were observed in the gene expression of ECM components.

Collagen type I (which is produced by both pre-chondrocyte mesenchymal cells and osteoblasts) can increase during the dedifferentiation of chondrocyte and OA; this process is also characterized by a disorganization of the ECM and presence of fibrotic repair tissue (62). In our study, Col1 gene expression increased significantly from the second to the fourth week of culture only with supplementation with FBS in $\mathrm{CH}$ enriched with HA. It is noteworthy that the presence of $\mathrm{PL}$ reduced the expression of Coll compared with the other conditions.
Moreover, addition of PL increased the gene expression of Col2, ACAN, and VCAN compared with the other conditions. This was particularly so when the scaffold was prepared with HA.

Together with reduction of Coll1 and increase of Coll2 and $A C A N$, the increase of VCAN is an important result considering its role in the interaction with the cells and with other ECM molecules to regulate the microenvironment that supports hyaline cartilage formation $(63,64)$.

Sox9 is a transcription factor that regulates the differentiation phase of chondrogenesis, while Runx2 is a transcription factor upregulated in the hypertrophic phenotype and during endochondral ossification (65). With PL treatment and the presence of HA in the scaffold, Sox9 increased only marginally in the longest experimental time. Regarding Runx2, PL maintains low expression levels, which are higher only in the presence of FBS.

In a similar way, molecular investigation verified the morphological phenotype capable of increased colonization and staining of ECM. Moreover, when cultured in 3D scaffolds with $\mathrm{HA}$, the long-term maintenance of chondrocyte phenotype was verified by a reduced gene expression of Col1 and Runx2.

Furthermore, treatment with PL has been confirmed to sustain the proliferation capacity of cultured chondrocytes $(29,66)$, in a similar way to the FBS.

However, it is also capable of maintaining/promoting chondrocyte differentiation potential in the 3D system (29, 67-69).

In a previous study, we observed that PL succeeded in maintaining a better pattern of gene expression of markers of mature articular chondrocytes compared with FBS, particularly for the percentage ranging from 5 to $10 \%$. In particular, the $5 \%$ PL concentration demonstrated to give a better balance between proliferation capacity and maintenance of differentiation (39).

Overall, morphological and biochemical analyses yielded noteworthy results on the effects of PL in combination with the culture in scaffolds enriched with HA.

$\mathrm{CH}$ and $\mathrm{HA}$ are natural materials and are biocompatible, biodegradable, non-toxic, and inexpensive (14), with chemical characteristics suitable for cartilage tissue engineering. In agreement with previous studies conducted on chondrocytes and stem cells of different origins, the enrichment with HA provide a remarkable microenvironment for the culture system $(61,70-72)$.

Furthermore, considering that FBS is not recommended for in vivo use (29), PL can be suggested as a good alternative.

In conclusion, the use of $3 \mathrm{D} \mathrm{CH}$ scaffold when $\mathrm{PL}$ is added as a substitute for FBS promotes the gene expression of most relevant ECM components. This indicates that this cultivation system enables a better maintenance of chondrocyte phenotype, highlighting an effective trade-off between proliferation and differentiation (73) and should be considered as a useful option in future application. Results of the present study are encouraging, and the validation of the construct with preclinical studies in both ectopic and mechanically loaded applications should continue. 


\section{DATA AVAILABILITY STATEMENT}

The raw data supporting the conclusions of this article will be made available by the authors, without undue reservation.

\section{AUTHOR CONTRIBUTIONS}

$\mathrm{PB}, \mathrm{ED}, \mathrm{FR}$, and $\mathrm{RB}$ contributed to conception and design of the study. ED, LE, AB, CB, MP, RR, MA, VCa, VCo, and

\section{REFERENCES}

1. Steinert AF, Ghivizzani SC, Rethwilm A, Tuan RS, Evans CH, Nöth U. Major biological obstacles for persistent cell-based regeneration of articular cartilage. Arthritis Res Ther. (2007) 9:213. doi: 10.1186/ar2195

2. Khademhosseini A, Vacanti JP, Langer R. Progress in tissue engineering. Sci Am. (2009). 300:64-71. doi: 10.1038/scientificamerican0509-64

3. Kalkan R, Nwekwo CW, Adali T. The use of scaffolds in cartilage regeneration. Crit Rev Eukaryot Gene Expr. (2018) 28:343-8. doi: 10.1615/CritRevEukaryotGeneExpr.2018024574

4. Ponomarev IV, Kochneva LM, Barnewitz D. Effect of 3D chondrocyte culturing conditions on the formation of extracellular matrix in cartilage tissue-engineering constructs. Bull Exp Biol Med. (2014) 156:548-55. doi: 10.1007/s10517-014-2394-3

5. Lynn AK, Brooks RA, Bonfield W, Rushton N. Repair of defects in articular joints. Prospects for material-based solutions in tissue engineering. $J$ Bone Jt Surg Ser B. (2004) 86:1093-99. doi: 10.1302/0301-620X.86B8.15609

6. Schlegel W, Nürnberger S, Hombauer M, Albrecht C, Vécsei V, Marlovits S. Scaffold-dependent differentiation of human articular chondrocytes. Int J Mol Med. (2008) 22:691-9. doi: 10.3892/ijmm_00000074

7. Barnewitz D, Endres M, Krüger I, Becker A, Zimmermann J, Wilke I, et al. Treatment of articular cartilage defects in horses with polymerbased cartilage tissue engineering grafts. Biomaterials. (2006) 27:2882-89. doi: 10.1016/j.biomaterials.2006.01.008

8. De Angelis E, Ravanetti F, Martelli P, Cacchioli A, Ivanovska A, Corradi A, et al. The in vitro biocompatibility of $\mathrm{d}-(+)$ raffinose modified chitosan: Twodimensional and three-dimensional systems for culturing of horse articular chondrocytes. Res Vet Sci. (2017) 115:310-7. doi: 10.1016/j.rvsc.2017.06.005

9. Frisbie DD, Lu Y, Kawcak CE, Dicarlo EF, Binette F, Mcilwraith CW. In vivo Evaluation of autologous cartilage fragment-loaded scaffolds implanted into equine articular defects compared with autologous chondrocyte implantation. Am J Sports Med. (2009) 37:71S-80S. doi: 10.1177/0363546509348478

10. Martins EAN, Michelacci YM, Baccarin RYA, Cogliati B, Silva LCLC. L. C. Evaluation of chitosan-GP hydrogel biocompatibility in osteochondral defects: an experimental approach. BMC Ve. Res. (2014) 10:197. doi: 10.1186/s12917-014-0197-4

11. Nixon AJ, Begum L, Mohammed HO, Huibregtse B, O'Callaghan MM, Matthews GL. Autologous chondrocyte implantation drives early chondrogenesis organized repair in extensive full- partial-thickness cartilage defects in an equine model. J Orthop Res. (2011) 29:1121-30. doi: $10.1002 /$ jor. 21366

12. Tan H, Chu CR, Payne KA, Marra KG. Injectable in situ forming biodegradable chitosan-hyaluronic acid based hydrogels for cartilage tissue engineering. Biomaterials. (2009) 30:2499-506. doi: $10.1016 /$ j.biomaterials.2008.12.080

13. Bianchera A, Salomi E, Pezzanera M, Ruwet E, Bettini R, Elviri L. Chitosan hydrogels for chondroitin sulphate controlled release: an analytical characterization. J Anal Methods Chem. (2014) 30:2499-506. doi: $10.1155 / 2014 / 808703$

14. Shahidi F, Abuzaytoun R. Chitin, chitosan, co-products: chemistry. production, applications, health effects. Adv Food Nutr Res. (2005) 49:93-135. doi: $10.1016 /$ S1043-4526(05)49003-8

15. Correia CR, Moreira-Teixeira LS, Moroni L, Reis RL, Van Blitterswijk CA, Karperien M, et al. Chitosan scaffolds containing hyaluronic acid for
PB performed laboratory preparation and testing organized the database. RS and PM performed the statistical analysis. PB and ED wrote the first draft of the manuscript. FR, RB, PB, and RS wrote sections of the manuscript. All authors contributed to manuscript revision, read, and approved the submitted version.

\section{FUNDING}

Open access institutional found for open access publication. cartilage tissue engineering. Tissue Eng Part C Methods. (2011) 17:717-30. doi: 10.1089/ten.tec.2010.0467

16. Di Martino A, Sittinger M, Risbud MV. Chitosan: A versatile biopolymer for orthopaedic tissue-engineering. Biomaterials. (2005) 26:5983-90. doi: 10.1016/j.biomaterials.2005.03.016

17. Lahiji A, Sohrabi A, Hungerford DS, Frondoza CG. Chitosan supports the expression of extracellular matrix proteins in human osteoblasts chondrocytes. J Biomed Mater Res. (2000) 51:586-95. doi: 10.1002/1097-4636(20000915)51:4<586::AID-JBM6>3.0.CO;2-S

18. Tan H, Wu J, Lao L, Gao C. Gelatin/chitosan/hyaluronan scaffold integrated with PLGA microspheres for cartilage tissue engineering. Acta Biomater. (2009) 5:328-37. doi: 10.1016/j.actbio.2008.07.030

19. Urban JPG. The chondrocyte: a cell under pressure. Rheumatology. (1994) 33:901-8. doi: 10.1093/rheumatology/33.10.901

20. Nair S, Remya NS, Remya S, Nair PD. A biodegradable in situ injectable hydrogel based on chitosan and oxidized hyaluronic acid for tissue engineering applications. Carbohyd Polym. (2011) 85:838-44. doi: 10.1016/j.carbpol.2011.04.004

21. Chen FM, Liu X. Advancing biomaterials of human origin for tissue engineering. Prog Polym Sci. (2016) 53:86-168. doi: 10.1016/j.progpolymsci.2015.02.004

22. Filardo G, Kon E, Roffi A, Di Matteo B, Merli ML, Marcacci M. Platelet-rich plasma: why intra-articular? A systematic review of preclinical studies and clinical evidence on PRP for joint degeneration. Knee Surg Sport Traumatol Arthrosc. (2015) 23:2459-74. doi: 10.1007/s00167-013-2743-1

23. Gobbi A, Lad D, Karnatzikos G. The effects of repeated intra-articular PRP injections on clinical outcomes of early osteoarthritis of the knee. Knee Surg Sport Traumatol Arthrosc. (2015) 23:2170-77. doi: 10.1007/s00167-014-2 987-4

24. Kon E, Filardo G, Di Matteo B, Marcacci M. prp for the treatment of cartilage pathology. Open Orthop J. (2013) 7:120-8. doi: $10.2174 / 1874325001307010120$

25. Moraes APL, Moreira JJ, Brossi PM, Machado TSL, Michelacci YM, Baccarin RYA. Short- and long-term effects of platelet-rich plasma upon healthy equine joints: Clinical and laboratory aspects. Can Vet J. (2015) 56:26246629.

26. Torricelli P, Fini M, Filardo G, Tschon M, Pischedda M, Pacorini A, et al. Regenerative medicine for the treatment of musculoskeletal overuse injuries in competition horses. Int Orthop. (2011) 35:1569-76. doi: $10.1007 / \mathrm{s} 00264-011-1237-3$

27. Tyrnenopoulou P, Diakakis N, Karayannopoulou M, Savvas I, Koliakos G. Evaluation of intra-articular injection of autologous platelet lysate (PL) in horses with osteoarthritis of the distal interphalangeal joint. Vet Q. (2016) 36:56-62. doi: 10.1080/01652176.2016.1141257

28. Al-Ajlouni J, Awidi A, Samara O, Al-Najar M, Tarwanah E, Saleh M, et al. Safety efficacy of autologous intra-articular platelet lysates in early intermediate knee osteoarthrosis in humans: a prospective open-label study. Clin J Sport Med. (2015) 25:524-8. doi: 10.1097/JSM.00000000000 00166

29. Hildner F, Eder MJ, Hofer $K$, Aberl J, Redl $H$, van Griensven $M$, et al. Human platelet lysate successfully promotes proliferation subsequent chondrogenic differentiation of adipose-derived stem cells: a comparison with articular chondrocytes. J Tissue EngRegen Med. (2015) 9:808-18. doi: $10.1002 /$ term. 1649 
30. Marmotti A, Rossi R, Castoldi F, Roveda E, Michielon G, Peretti GM. PRP and Articular cartilage: a clinical update. Biomed Res Int. (2015). doi: 10.1155/2015/542502

31. Roffi A, Filardo G, Assirelli E, Cavallo C, Cenacchi A, Facchini A, et al. Does platelet-rich plasma freeze-thawing influence growth factor release and their effects on chondrocytes and synoviocytes? Biomed Res Int. (2014) 23:2459-74. doi: $10.1155 / 2014 / 692913$

32. Ramezanifard R, Kabiri M, Hanaee Ahvaz H. Effects of platelet rich plasma and chondrocyte co-culture on MSC chondrogenesis, hypertrophy and pathological responses. EXCLI J. (2017) 16:1031-45.

33. Bendinelli P, Matteucci E, Dogliotti G, Corsi MM, Banfi G, Maroni P, et al. Molecular basis of anti-inflammatory action of platelet-rich plasma on human chondrocytes: Mechanisms of NF-кB inhibition via HGF. J Cell Physiol. (2010) 225:757-66. doi: 10.1002/jcp.22274

34. Cavallo C, Filardo G, Mariani E, Kon E, Marcacci M, Pereira Ruiz MT, et al. Comparison of platelet-rich plasma formulations for cartilage healing: an in vitro study. J Bone Jt Surg Ser A. (2014) 96:423-9. doi: 10.2106/JBJS.M.00726

35. Chien CS, Ho HO, Liang YC, Ko PH, Sheu MT, Chen CH. Incorporation of exudates of human platelet-rich fibrin gel in biodegradable fibrin scaffolds for tissue engineering of cartilage. J Biomed Mater Res. Part B Appl Biomater. (2012) 100B:948-55. doi: 10.1002/jbm.b.32657

36. Stokes DG, Liu G, Dharmavaram R, Hawkins D, Piera-Velazquez S, Jimenez SA. Regulation of type-II collagen gene expression during human chondrocyte de-differentiation recovery of chondrocyte-specific phenotype in culture involves Sry-type high-mobility-group box (SOX) transcription factors. Biochem J. (2001) 360:461-70. doi: 10.1042/bj3600461

37. Xie A, Nie L, Shen G, Cui Z, Xu P, Ge H, et al. The application of autologous platelet-rich plasma gel in cartilage regeneration. Mol Med Rep. (2014) 10:1642-8. doi: 10.3892/mmr.2014.2358

38. Burnouf T, Strunk D, Koh MBC, Schallmoser K. Human platelet lysate: replacing fetal bovine serum as a gold standard for human cell propagation? Biomaterials. (2016) 76:371-87. doi: 10.1016/j.biomaterials.2015. 10.065

39. De Angelis E, Cacchioli A, Ravanetti F, Bileti R, Cavalli V, Martelli P, et al. Gene expression markers in horse articular chondrocytes: chondrogenic differentiaton in vitro depends on the proliferative potential and ageing. Implication for tissue engineering of cartilage. Res Vet Sci. (2020) 128:107-17. doi: 10.1016/j.rvsc.2019.10.024

40. Schallmoser K, Bartmann C, Rohde E, Reinisch A, Kashofer K, Stadelmeyer E, et al. Human platelet lysate can replace fetal bovine serum for clinicalscale expansion of functional mesenchymal stromal cells. Transfusion. (2007) 47:1436-46. doi: 10.1111/j.1537-2995.2007.01220.x

41. O'Connell G, Garcia J, Amir J. 3D Bioprinting: new directions in articular cartilage tissue engineering. ACS Biomater Sci Eng. (2017) 3:2657-68. doi: 10.1021/acsbiomaterials.6b00587

42. Singh YP, Bandyopadhyay A, Mandal BB. 3D Bioprinting using cross-linkerfree silk-gelatin bioink for cartilage tissue engineering. ACS Appl Mater Interfaces. (2019) 11:33684-96. doi: 10.1021/acsami.9b11644

43. Lee J, Ko M, Joo CK. Rho plays a key role in TGF- $\beta 1$-induced cytoskeletal rearrangement in human retinal pigment epithelium. J Cell Physiol. (2008) 216:520-6. doi: 10.1002/jcp.21424

44. Toh WS, Spector M, Lee EH, Cao T. Biomaterial-mediated delivery of microenvironmental cues for repair and regeneration of articular cartilage. Mol Pharm. (2011) 7:544-59. doi: 10.1021/mp100437a

45. Bergonzi C, Di Natale A, Zimetti F, Marchi C, Bianchera A, Bernini F, et al. Study of 3D-printed chitosan scaffold features after different post-printing gelation processes. Sci Rep. (2019) 9:362. doi: 10.1038/s41598-018-36613-8

46. Jeyakumar V, Niculescu-Morzsa E, Bauer C, Lacza Z, Nehrer S. Platelet-rich plasma supports proliferation and redifferentiation of chondrocytes during in vitro expansion. Front Bioeng Biotechnol. (2017) 5. doi: 10.3389/fbioe.2017.00075

47. Bettini R, Romani AA, Morganti MM, Borghetti AF. Physicochemical cell adhesion properties of chitosan films prepared from sugar phosphate-containing solutions. Eur J Pharm Biopharm. (2008) 68:74-81. doi: 10.1016/j.ejpb.2007.03.026

48. Elviri L, Foresti R, Bergonzi C, Zimetti F, Marchi C, Bianchera A, et al. Highly defined 3D printed chitosan scaffolds featuring improved cell growth. Biomed Mater. (2017) 12:045009. doi: 10.1088/1748-605X/aa7692
49. Cacchioli A, Ravanetti F, Alinovi R, Pinelli S, Rossi F, Negri M, et al. Cytocompatibility and cellular internalization mechanisms of $\mathrm{SiC} / \mathrm{SiO} 2$ nanowires. Nano Lett. (2014) 14:4368-75. doi: 10.1021/nl501255m

50. Ravanetti F, Borghetti P, De Angelis E, Chiesa R, Martini FM, Gabbi $\mathrm{C}$, et al. In vitro cellular response and in vivo primary osteointegration of electrochemically modified titanium. Acta Biomater. (2010) 6:1014-24. doi: 10.1016/j.actbio.2009.09.022

51. Livak KJ, Schmittgen TD. Analysis of relative gene expression data using realtime quantitative PCR and the $2^{-\Delta \Delta C T}$ method. Methods. (2001) 25:402-8. doi: $10.1006 /$ meth.2001.1262

52. Schmittgen TD, Livak KJ. Analyzing real-time PCR data by the comparative $\mathrm{C}(\mathrm{T})$ methodSchmittgen TD. Livak KJ, (2008). Analyzing real-time PCR data by the comparative C(T) method. Nat. Protoc. (2008) 3:1101-08. Nat. Protoc. doi: $10.1038 /$ nprot.2008.73

53. Danišovič L, Varga I, Zamborský R, Böhmer D. The tissue engineering of articular cartilage: Cells, scaffolds and stimulating factors. Exp Biol Med. (2012) 237:10-7. doi: 10.1258/ebm.2011.011229

54. Campos Y, Almirall A, Fuentes G, Bloem HLKaijzel EL, Cruz LJ. Tissue engineering: an alternative to repair cartilage. Tissue Eng Part B Rev. (2019) 25:357-73. doi: 10.1089/ten.teb.2018.0330

55. Li S, Tian X, Fan J, Tong H, Ao Q, Wang X. Chitosans for tissue repair and organ three-dimensional (3D) bioprinting. Micromachines. (2019) 10:765-95. doi: $10.3390 / \mathrm{mil} 10110765$

56. Giretova M, Medvecky L, Petrovova E, Cizkova D, Danko J, Mudronova $\mathrm{D}$, et al. Polyhydroxybutyrate/Chitosan 3D scaffolds promote in vitro and in vivo chondrogenesis. Appl Biochem Biotechnol. (2019) 189:556-75. doi: 10.1007/s12010-019-03021-1

57. Wang X, Liu C. 3D bioprinting of adipose-derived stem cells for organ manufacturing. Adv Exper Med Biol. (2018) 1078:3-14. doi: 10.1007/978-981-13-0950-2_1

58. Zhang R, Ma J, Han J, Zhang W, Ma J. Mesenchymal stem cell related therapies for cartilage lesions and osteoarthritis. Am J Transl Res. (2019) 11:6275-89.

59. Conoscenti G, Schneider T, Stoelzel K, Carfi Pavia F, Brucato V, Goegele C, et al. PLLA scaffolds produced by thermally induced phase separation (TIPS) allow human chondrocyte growth and extracellular matrix formation dependent on pore size. Mater Sci Eng C. (2017) 80:449-59. doi: 10.1016/j.msec.2017.06.011

60. Mollon B, Kandel R, Chahal J, Theodoropoulos J. The clinical status of cartilage tissue regeneration in humans. Osteoarthr Cartil. (2013) 21:1824-33. doi: 10.1016/j.joca.2013.08.024

61. Yamane S, Iwasaki N, Majima T, Funakoshi T, Masuko T, Harada K, et al. Feasibility of chitosan-based hyaluronic acid hybrid biomaterial for a novel scaffold in cartilage tissue engineering. Biomaterials. (2005) 26:611-9. doi: 10.1016/j.biomaterials.2004.03.013

62. Semevolos SA, Nixon AJ, Brower-Toland BD. Changes in molecular expression of aggrecan and collagen types I, II, and X, insulin-like growth factor-I, and transforming growth factor- $\beta 1$ in articular cartilage obtained from horses with naturally acquired osteochondrosis. Am J Vet Res. (2001) 62:1088-94. doi: 10.2460/ajvr.2001.62.1088

63. Matsumoto K, Kamiya N, Suwan K, Atsumi F, Shimizu K, Shinomura T, et al. Identification and characterization of versican/PG-M aggregates in cartilage. J Biol Chem. (2006) 281:18257-63. doi: 10.1074/jbc.M510330200

64. Taylor DW, Ahmed N, Parreno J, Lunstrum GP, Gross AE, Diamandis EP, et al. Collagen type XII and versican are present in the early stages of cartilage tissue formation by both redifferentating passaged and primary chondrocytes. Tissue Eng Part A. (2015) 21:683-93. doi: 10.1089/ten.tea.201 4.0103

65. Yuan X, Liu H, Huang H, Liu H, Li L, Yang J, Shi W, et al. The Key role of canonical wnt/ $\beta$-catenin signaling in cartilage chondrocytes. Curr Drug Targets. (2015) 17:475-84. doi: 10.2174/1389450116666150825 112623

66. Kaps C, Loch A, Haisch A, Smolian H, Burmester GR, Häupl T, et al. Human platelet supernatant promotes proliferation but not differentiation of articular chondrocytes. Med Biol Eng Comput. (2002) 40:485-90. doi: 10.1007/BF023 45083

67. Moroz A, Deffune E. Platelet-rich plasma and chronic wounds: remaining fibronectin may influence matrix remodeling and regeneration success. Cytotherapy. (2013) 15:1436-9. doi: 10.1016/j.jcyt.2013.05.019 
68. Tekari A, Luginbuehl R, Hofstetter W, Egli RJ. Transforming growth factor beta signaling is essential for the autonomous formation of cartilagelike tissue by expanded chondrocytes. PLoS ONE. (2015) 10:e0120857. doi: 10.1371/journal.pone.0120857

69. Yin W, Xu H, Sheng J, Xu Z, Xie X, Zhang C. Comparative evaluation of the effects of platelet-rich plasma formulations on extracellular matrix formation and the NF-кB signaling pathway in human articular chondrocytes. Mol Med Rep. (2017) 15:2940-8. doi: 10.3892/mmr.2017.6365

70. Kim D-D, Kim D-H, Son Y-J. Three-dimensional porous scaffold of hyaluronic acid for cartilage tissue. Engineering. (2010) 8:329-49. doi: 10.1007/8415_2010_51

71. Mallick SP, Rastogi A, Tripathi S, Srivastava P. Strategies on process engineering of chondrocyte culture for cartilage tissue regeneration. Bioprocess Biosyst Eng. (2017) 40:601-10. doi: 10.1007/s00449-016-1724-4

72. Toh WS, Lee EH, Cao T. Potential of human embryonic stem cells in cartilage tissue engineering and regenerative medicine. Stem Cell Rev Rep. (2011) 7:544-59. doi: 10.1007/s12015-010-9222-6
73. Elder S, Thomason J. Effect of platelet-rich plasma on chondrogenic differentiation in three-dimensional culture. Open Orthop. J. (2014) 8:78-84. doi: 10.2174/18743250014080 10078

Conflict of Interest: The authors declare that the research was conducted in the absence of any commercial or financial relationships that could be construed as a potential conflict of interest.

Copyright (C) 2021 De Angelis, Saleri, Martelli, Elviri, Bianchera, Bergonzi, Pirola, Romeo, Andrani, Cavalli, Conti, Bettini, Passeri, Ravanetti and Borghetti. This is an open-access article distributed under the terms of the Creative Commons Attribution License (CC BY). The use, distribution or reproduction in other forums is permitted, provided the original author(s) and the copyright owner(s) are credited and that the original publication in this journal is cited, in accordance with accepted academic practice. No use, distribution or reproduction is permitted which does not comply with these terms. 